\title{
Factors Affecting the Non-Adherence to Inhalational Medication in Bronchial Asthma: A Cross Sectional Study in a Tertiary Care Hospital
}

\author{
Mohammad Abdus Sattar Sarker, ${ }_{1}^{1}$ Umma Salma, ${ }^{2}$ Nahida Zafrin, ${ }^{3}$ M A Kashem, ${ }^{4}$ Sudip Ranjan Deb, ${ }^{5}$ \\ A K M Humayon Kabir 6
}

\begin{abstract}
Introduction: Modern management of bronchial asthma requires prolonged medications to prevent symptoms and airflow limitations. An important issue in proper management of bronchial asthma is adherence to treatment.

Objective: To see the non-adherence rate to inhalational medication in bronchial asthma patient as well as to see the factors responsible for non-adherence.

Materials and Method: It was a cross sectional study conducted from Ist September 2017 to 3/st March 2018 in Medicine unit of Sir Salimullah Medical College and Hospital (SSMCH).

Result: Among the 136 respondents $70 \%$ were male and $30 \%$ were female. Non adherent rate was $93.7 \%$ for male and $100 \%$ for female. High cost of medicine, poor counseling, lack of family support, lack of immediate efficacy, forgetfullness, knowledge on how to use device are the main factors for non-adherence.

Conclusion: The rate of non-adherence is very high amongst the participants. Therefore promoting optimal medication adherences through education, proper counseling is essential to optimize the benefits of treatment.
\end{abstract}

Key words: Non-Adherence, inhalational medication, bronchial asthma.

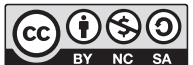

DOI: https://doi.org/l0.3329/jom.v2Iil.44/08

Copyright: (C) 2020 Khanom M. This is an open access article published under the Creative Commons Attribution-NonCommercial-NoDerivatives 4.0 International License, which permits use, distribution and reproduction in any medium, provided the original work is properly cited, is not changed in any way and it is not used for commercial purposes.

Received: 29 July, 2019;

Accepted: 17 October, 2019

\section{Introduction:}

Asthma is a chronic inflammatory condition of the airways that affect around 358 million people worldwide ${ }^{1}$. It is a serious global health problem with an increasing prevalence worldwide. People of the low- and middle-income countries are mostly affected. Estimates indicate that India has 20-28 million asthmatics and the prevalence amongst children (510 years) is $10-15 \%$. People of all ages are affected by this

1. Associate Professor (Medicine), Sir Salimullah Medical College, Dhaka.

2. Associate Professor (Medicine), Dhaka National Medical College and Hospital.

3. Assistant Professor (Medicine), Sylhet MAG Omani Medical College.

4. Professor (Medicine), Dhaka Medical College, Dhaka.

5. Associate Professor (Medicine), Mugda Medical College, Dhaka.

6. Associate Professor (Medicine), Dhaka Medical College, Dhaka.

Corresponding author: Dr. Mohammad Abdus Sattar Sarker, Associate Professor (Medicine), Sir Salimullah Medical College, Dhaka. chronic airway disorder with higher burden of disability. ${ }^{2}$ In 2015 more than 397100 deaths were caused by asthma and most of which occurred in the developing countries. ${ }^{3}$

Modern management of bronchial asthma requires prolonged medications. Medications for asthma reverse and prevent symptoms and airflow limitations. A key issue in proper management of bronchial asthma is adherence to treatment. Poor compliance to prescribed medicine increases morbidity and mortality and it is increasingly being documented that long term compliance or adherence to prescribed therapy is hard to attain. ${ }^{4}$ Studies has reported that $50 \%$ of the patients with a chronic disease do not use their medication at all or do not use it as prescribed. ${ }^{5}$

\section{There are two types of non-adherence}

1. Unintentional non adherence results from practical barrier to adherence such as
a) Misunderstanding the prescribing instructions
b) Language barriers
c) Frequently and understandability, forgetfulness

2. Intentional non adherence results from the patients decisions not to take the medication as prescribed i.e. to 
take less or more or to take it differently the prescribed, such as:

a) Patient may doubt the necessity of taking a daily medication for a condition that they experience episodically, while

b) They may have concerns about potential adverse effect of inhaled steroids. ${ }^{6}$

Adherence with medication regimen is essential for attaining maximal therapeutic benefits. ${ }^{7}$ Multiple studies have shown that medication adherence decreases as the number of medications prescribed, the dosing frequency and the duration of the treatment increases. ${ }^{8}$ Non adherence may be in form of not fulfilling prescriptions, omission of doses, incorrect medications, incorrect dosages or schedules, premature, discrimination of drugs, not following advice to avoid allergens and suboptimal inhalation techniques. ${ }^{9}$

The present study was undertaken to assess the medication adherence and to identify the factors that influence patients' adherence with prescribed medication.

\section{Materials and Methods:}

It was a cross sectional study conducted from 1st September 2017 to 31st March 2018 in medicine unit of Sir Salimullah Medical College and Hospital (SSMCH). A pretested selfadministered structured questionnaire was used to collect data from the respondent. To comply with the ethical issues prior informed consent was taken from each participant. The main objective of the study was to evaluate the nonadherence rate to inhale medication in bronchial asthma patient as well as to evaluate the factor responsible for nonadherence.

\section{Results:}

Among the 136 respondents 85 (70\%) were male and $41(30 \%)$ were female. Among the male respondents highest respondents belong to age group 40-59 (51\%) and among the female respondents the highest respondents belongs to age group 60-79 (46\%) (Table 1).

It was observed that drug adherence was inversely proportional to age i.e. with the increasing age drug adherence rate is gradually decreased. Among the female respondent $100 \%$ were non adherent to medicine and there was no influence of age in adherence pattern in case female patient.

It was clear among the male respondent that drug adherence rate is highest amongst the university graduate, though rate of adherence was still very low (only 12.12\%). All respondents were non adherent amongst those who are illiterate and/or studied up to primary school. Female respondents were 100\% non-adherent whatever maybe the educational status (Table 2).

Among the male asthma patients, 75 (78.9\%) were smoker and $4(4.21 \%)$ patients were nonsmoker. Among the female asthma patients 4 (9.4\%) were smoker and 37 (90\%) were nonsmoker (Table 3 ). There is a difference of smoking pattern between make and female asthma patients. Among the participants, 43 (45.26\%) male had family history of bronchial asthma and $14(66.66 \%)$ female had history of bronchial asthma.

From table 4 it is observed that, within first five years of diagnosis of asthma drug compliance rate is relatively high (7.5\%) in comparison to those who had bronchial asthma for $>15$ years $(0 \%)$. In case of females there is no relationship of compliance with duration of asthma diagnosis. All of them were non adherent. In case of male respondents drug adherence rate gradually increases with increase of income. Highest drug adherence of $28 \%$ is observed among those who had monthly income of more than Tk 70000 per month.

In male patients those who had comorbidity they were more non adherent (97\%). High cost of medicine was the primary reason for drug non-adherence in both male (49.47\%) and female group (48.48\%). Treatment considered unnecessary after the initial recovery of acute attack i.e. lack of proper counseling about medication was the second most common cause of non-adherence among both age groups. Other factor of for non-adherence were lack family support, lack of immediate effect after taking inhaled steroid, forget to take medication, unavailability of medication, fear about the side effects etc.

Table 1: Pattern of non-adherenec in different age groups of male and female asthma patients $(\mathrm{N}=136)$

\begin{tabular}{lccccccc}
\hline Age & \multicolumn{2}{c}{ Male } & \multicolumn{3}{c}{ Female } \\
& Total & C & $\%$ & NC & $\%$ & Total & $\%$ \\
\hline $20-39$ & 4 & 2 & 50.00 & 2 & 50.00 & 2 & All NC \\
$40-59$ & 49 & 3 & 6.12 & 46 & 93.88 & 11 & \\
$60-79$ & 27 & 1 & 3.70 & 26 & 96.30 & 19 & \\
80 and above & 15 & 0 & 0.00 & 15 & 100.00 & 9 & \\
\hline
\end{tabular}

$\mathrm{C}=$ compliant, $\mathrm{NC}=$ Non-compliant 
Table 2: Non-adherence in patients according to educational level $(N=136)$

\begin{tabular}{|c|c|c|c|c|c|c|c|c|c|c|}
\hline \multirow[t]{2}{*}{ Educational Status } & \multicolumn{5}{|c|}{ Male } & \multicolumn{4}{|c|}{ Female } & \multirow[b]{2}{*}{$\%$} \\
\hline & Total & $\mathrm{C}$ & $\%$ & $\mathrm{NC}$ & $\%$ & Total & $\mathrm{C}$ & $\%$ & $\mathrm{NC}$ & \\
\hline University & 33 & 4 & 12.12 & 29 & 87.88 & 5 & 0 & 0 & 5 & 100 \\
\hline College & 30 & 2 & 6.67 & 28 & 93.33 & 6 & 0 & 0 & 6 & 100 \\
\hline School & 22 & 0 & 0 & 22 & 100 & 14 & 0 & 0 & 14 & 100 \\
\hline Illiterate & 10 & 0 & 0 & 10 & 100 & 16 & 0 & 0 & 16 & 100 \\
\hline
\end{tabular}

Table 3 : Smoking pattern across gender (Full)

\begin{tabular}{lccccc}
\hline Habit of Smoking & Male & $\%$ & Female & $\%$ & $\mathrm{p}$-Value \\
\hline Smoker & 75 & 78.95 & 4 & 9.76 & 0.001 \\
Non-Smoker & 4 & 4.21 & 37 & 90.24 & 0.001 \\
\hline
\end{tabular}

Table 4: Non-compliance of asthma medication among patients with their duration of disease $(N=136)$

\begin{tabular}{|c|c|c|c|c|c|c|}
\hline \multirow{2}{*}{$\begin{array}{l}\text { Length of time patient has Asthma } \\
\text { (In Years) }\end{array}$} & \multicolumn{5}{|c|}{ Male } & \multirow[t]{2}{*}{ Female } \\
\hline & Total & $\mathrm{C}$ & $\%$ & $\mathrm{NC}$ & $\%$ & \\
\hline 1 to 5 & 4 & 3 & 75 & 1 & 25 & 3 \\
\hline 6 to 10 & 23 & 2 & 8.70 & 21 & 91.30 & 7 \\
\hline 11 to 15 & 43 & 1 & 2.33 & 42 & 97.67 & 15 \\
\hline 16 to above & 25 & 0 & 0 & 25 & 100 & 16 \\
\hline
\end{tabular}

Table 5: Effect of financial situation on adherence

\begin{tabular}{lcccccc}
\hline Economic Status & \multicolumn{7}{c}{ Per month income } \\
\cline { 2 - 7 } & Male & C & $\%$ & NC & $\%$ & Female \\
\hline$<10000 /$ month & 1 & 0 & 0 & 1 & 100 & 1 \\
10000 to 30000/month & 4 & 0 & 0 & 4 & 100 & 12 \\
30000 to 50000/month & 36 & 1 & 2.78 & 35 & 97.22 & 19 \\
50000 to 70000/month & 47 & 3 & 6.38 & 44 & 93.62 & 8 \\
$>70000 /$ month & 7 & 2 & 28.57 & 5 & 71.43 & 1 \\
\hline
\end{tabular}

Table 6: Effect of comorbidity

\begin{tabular}{lccccccccccc}
\hline Co morbidity & Male & $\mathrm{C}$ & $\%$ & $\mathrm{NC}$ & $\%$ & Female & $\mathrm{C}$ & $\%$ & $\mathrm{NC}$ & $\%$ & $\mathrm{p}$-Value \\
\hline Yes & 85 & 2 & 2.35 & 83 & 97.65 & 32 & 0 & 0 & 32 & 100 & 0.001 \\
No & 10 & 4 & 40 & 6 & 60 & 9 & 0 & 0 & 9 & 100 & 0.001 \\
\hline
\end{tabular}


Table 8: Factors for non-adherence

\begin{tabular}{lccccc}
\hline Factors for Medication non-adherence & \multicolumn{2}{c}{ Male } & \multicolumn{2}{c}{ Female } & p-value \\
& Total & $\%$ & Total & $\%$ & \\
\hline High Cost Medication/Monitory Reason & 47 & 49.47 & 20 & 48.78 & 0.669 \\
Treatment consider after initial recovery of & 14 & 14.74 & 5 & 12.20 & 0.596 \\
acute attack/lack of counselling about medication & & & & & \\
Lack of family support & 7 & 7.37 & 8 & 19.51 & 0.053 \\
Lack of immediate effect after taking inhaled steroid & 6 & 6.32 & 3 & 7.32 & 0.904 \\
Forget to take/occupation related problem & 7 & 7.37 & 2 & 4.88 & 0.533 \\
Poor inhale technique/Trouble in operating dispenser & 3 & 3.16 & 1 & 2.44 & 0.775 \\
Difficulty to get medication in nearby pharmacy & 2 & 2.11 & 1 & 2.44 & 0.946 \\
Fear about side effect of the drugs & 3 & 3.16 & 1 & 2.44 & 0.775 \\
\hline
\end{tabular}

\section{Discussion:}

Bronchial asthma, a chronic lung disease that affects people of all ages, races and ethnic groups, is a growing concern throughout the world. In this study non adherence to treatment was more common than usually suspected $(>90.5 \%$ in case of male and $100 \%$ in case of female). Gajanen et all found non-adherence rate was $20 \%$ to $80 \%$ in patients with asthma and other chronic diseases. ${ }^{10}$

Out of 95 male asthma patients, non-adherence rate was highest among patients aged 80 or more (100\%). Nonadherence rate was $96.29 \%$ and $93.87 \%$ among the age group (60 to 79 ) years and ( 40 to 59 ) years respectively. Among the 41 female patients, all of them were non-adherent to medication. Katz et all reported that among the asthma patients, non-adherence rate was $85 \%$ in case of male and $89 \%$ in case of female. ${ }^{11}$ In our country female patients are neglected and commonly dependent towards the family members. So, no-adherence rate is very high among them.

In this study report, it was observed that non-adherence rate is highest (100\%) among the illiterate patients. This result corresponds with the result of Kaiser et all where among the illiterate respondents' non-compliance rate was $75 \% .{ }^{12}$ Nonadherence rate gradually increases with the increased duration of illness. Here adherence rate was $7.5 \%$ during $1 \mathrm{st}$ year of diagnosis of asthma but adherence rate was $0 \%$ when disease duration exceeds $>15$ years. Asnakew et all got the similar findings in their study i.e. non-adherence rate was $>90 \%$ when disease duration rate exceeds $>15$ years. ${ }^{13}$

Among the respondents, high cost of medicine was the primary reason for drug non-adherence in both male (49.4\%) and female $(48.48 \%)$ as inhalers and rotahalers are very costly. Majority of the patients enrolled were from middle class family and from low socio-economic groups, so they couldn't afford the cost of medications. Price of medicine is a less important factors for non-adherence where medication costs are covered by insurance. ${ }^{14-15}$

Treatment considered unnecessary after initial recovery of acute attack was the second most common cause of nonadherence. $14 \%$ male and $12 \%$ female respondents discontinued their prescribed inhaler medication after initial recovery. Similar study carried out by Mehuys et all found that pharmacists' intervention substantially improved both the inhalation technique and medication adherence. ${ }^{16}$ Lindberg et all reported that asthma education and education about inhaled medications from hospital-based specialist nurses improved adherence and clinical outcomes in asthma patients.

$6 \%$ male patients and $7 \%$ female patients were reported that they don't get any immediate effect after taking inhaled medication. This is a common problem mentioned in other similar type of study. ${ }^{17}$ This may be due to progression of disease and inappropriate therapy. Hence clinical and trained nurses can solve this problem by proper counseling of the patients.

Three percent male patients and 1\% female patients discontinued the inhaler due to trouble in operating the dispenser. Some percentage of patients discontinued the medication due to fear of side effects. These problems can be mitigated if we can give proper training to the patient by the skilled nurses and pharmacists.

\section{Conclusion:}

The rate of non-adherence to inhalational anti-asthmatics is high. High cost of medicine, lack of financial and family support, lack of education of proper use of inhalational antiasthmatic medications, poly pharmacy and co-morbidities have been identified to have affected non-adherence rate. 
Therefore, promoting optimal medication adherences through education, proper consultation is essential to optimize the benefits of treatment.

\section{Conflict of interest: None.}

\section{References:}

1. Vos T, Barber RM, Bell B, Bertozzi-Villa A, Biryukov S, Bolliger I et al. Global, regional, and national incidence, prevalence, and years lived with disability for 301 acute and chronic diseases and injuries in 188 countries, 1990-2013: a systematic analysis for the global burden of disease study 2013. Lancet. 2015;386(9995):743.

2. Van Gemert F, Van der Molen T, Jones R, Chavannes N. The impact of asthma and COPD in sub-Saharan Africa. Prim Care Respir J. 2011;20:240-8.

3. Sharma S, Shrama R, Sharma M, Verma M. Association between Bronchial asthma and Allergic Rhinitis: A Crosssectional Study. International Multispecialty Journal of Health. 2016;2:32-37

4. Chochrane GM. Compliance and outcomes in patients with asthma. Drugs 1996; 52:S12-S19.

5. Deenen T, Klip EC. Coping with asthma. Respir Med 1993; 87:S67-S70.

6. Horne R. Reasons for poor asthma control 3: Patients beliefs and adherence. Respir Med. 2008;102:1681-93.

7. Rigby D. Adherence assessment tools: Drugs don't work when they're not taken. The Australian Journal of Pharmacy 2007;88:32-3.
8. Weinstein AG. Should patients with persistent severe asthma be monitored for medication adherence? Ann Allergy Asthma Immunol. 2005;94:251-57.

9. Singh M, Kansra S. Adherence Issue in Asthma. Indian pediatrics 2006 Dec;43:1050-1055.

10. Gaude GS. Factors Affecting Non-adherence in Bronchial Asthma and Impact of Health Education. Indian J Allergy Asthma Immunol. 2011; 25(1):1-8

11. Katz Y, Goldberg M. Non-adherence, Non-compliance or Non-concordance in Asthma: Patients not Following the Medical Regimen. IMAJ 2007;9:389-90.

12. Kaisar HB. Compliance and non-compliance in asthma. Allergy Asthma Proc 2007; 28:514-6.

13. Ayele AA, Tegegn HG. Non adherence to inhalational medications and associated factors among patients with asthma in a referral hospital in Ethiopia, using validated tool TAI. Asthma Res Pract., 2017; 3: 7.

14. Williams $1 \mathrm{~K}$, Joseph Cl, Peterson El, et al. Race-ethnicity, crime, and other factors associated with adherence to inhaled corticosteroids. J Allergy Clin Immunol 2007; 119:168 -175.

15. Lindberg M, Estrom J, Moller M, Ahlner J. Asthma care and factors affecting medication compliance: The patient point of view. Intern J Quality Health Care 2001;13:375-383.

16. Johnson G, David CMK, Rambha T, Kay S. Factors associated with medication non-adherence in patients with COPD. Chest 2005;128:3198-3204.

17. Mehuys E, Bortel LV, Bolle LD, Tongelen IV, Annemans L, Remon JP et al. Effectiveness of pharmacist intervention for asthma control improvement. Eur Respir J 2008;31:790-9. 